\title{
Erratum to: Condensation of Pseudomagnons in a Two-Dimensional Anisotropic $S=1$ Pseudospin System
}

\author{
E. V. Vasinovich ${ }^{a, *}$, A. S. Moskvin ${ }^{a}$, and Yu. D. Panov ${ }^{a}$ \\ ${ }^{a}$ Ural Federal University Named after the First President of Russia B.N. Yeltsin, Yekaterinburg, 620002 Russia \\ *e-mail:e.vasinovich@gmail.com \\ Received November 21, 2018
}

DOI: $10.1134 / \mathrm{S} 1063783419010293$

E-mail address of the corresponding author should read: e.vasinovich@gmail.com

The original article can be found online at https://doi.org/10.1134/S1063783418110331. 